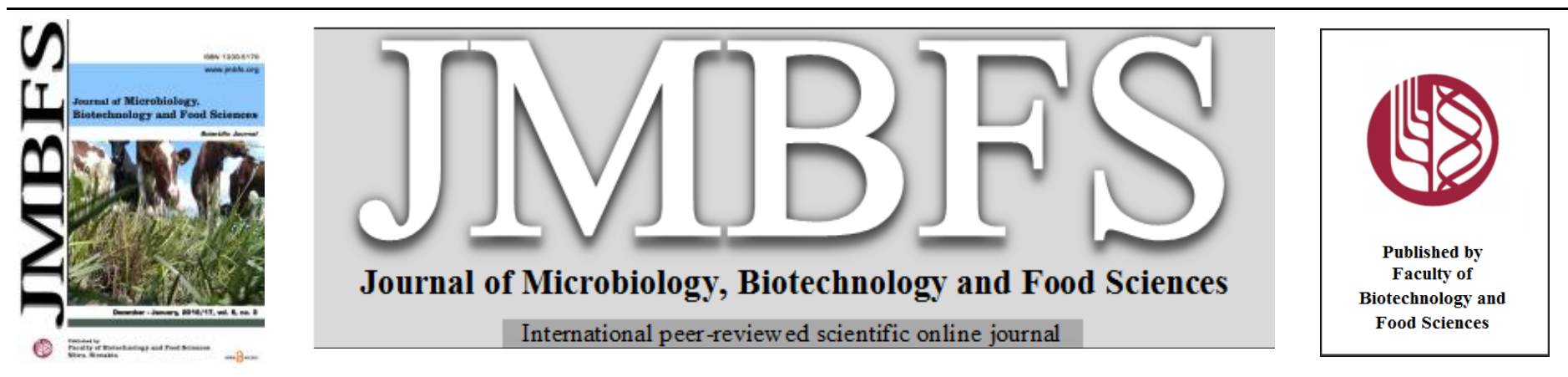

\title{
ISOLATION AND CHARACTERIZATION OF Fusarium solani CAUSING SOYBEAN SUDDEN DEATH SYNDROME IN KOREA
}

\author{
Puji Lestari*'T ${ }^{\text {IF }}$ Suli Sun ${ }^{2}$, Hokyeong Son ${ }^{3}$, Yin-Won Lee ${ }^{3}$, and Suk-Ha Lee
}

Address(es): Dr. Puji Lestari,

${ }^{1}$ Indonesian Center for Agricultural Biotechnology and Genetic Resources Research and Development - IAARD, Jl. Tentara Pelajar No. 3A, Bogor 16111, Indonesia; +62-251-8337975 Fax: +62-251-8338820.

${ }^{2}$ Institute of Crop Science/National Key Facilities for Crop Gene Resources and Genetic Improvement, Chinese Academy of Agricultural Sciences, Beijing 100081,

China.

${ }^{3}$ Department of Agricultural Biotechnology and Center for Fungal, Pathogenesis, Seoul National University, Seoul 151-921, Korea.

${ }^{4}$ Department of Plant Science and Research Institute for Agriculture and Life Sciences, Seoul National University, Seoul 151-921, Korea.

${ }^{\boldsymbol{T}}$ These authors contributed equally to this work.

*Corresponding author: sukhalee@ snu.ac.kr; plestari129@yahoo.com

doi: 10.15414/jmbfs.2016/17.6.3.950-955

\section{ARTICLE INFO}

Received 1. 8. 2016

Revised 9. 10. 2016

Accepted 25. 10. 2016

Published 1. 12. 2016

Regular article OPEN $\partial_{\text {ACCESS }}$

\begin{abstract}
Soybean sudden death syndrome (SDS), caused by members of the Fusarium solani species complex, is an important disease leading to substantial yield reductions. The threat of soybean SDS is becoming serious in Korea, probably due to changes in the climate favoring the prevalence of this disease. In this study, after isolating Fusarium spp. from root rot-symptomatic soybean, we determined that $F$. solani was a causal agent of soybean SDS based on morphological and molecular characterization as well as Koch's postulate. From 2009 to 2011, a total of nine isolates of Fusarium solani were collected from major soybean fields, Korea. Morphological and TEF-1a sequence analyses confirmed a variety of nine $F$. solani isolates. All $F$. solani isolates were close with $F$. solani species from Asia and mostly belonged to $F$. solani f. sp. pisi (SSLP14, 15, 16,19, and 20). Based on homology analysis of both ITS and TEF-1 $\alpha$, some isolates (SSLP2, 18, and 22) were similar to $F$. solani causing human eye keratitis, indicating a shared pathogenicity both on humans and plants. In a pathogenicity test, we observed hyphae in both xylem and phloem tissues from discolored roots and basal stems of plants exhibiting foliar SDS symptoms, indicating its contribution to foliar symptoms. Based on the differential reactions of soybean plant genotypes to $F$. solani isolates, one indigenous $F$. solani isolates, SSLP15 was identified having the highest levels of virulence. In addition, Danbaekkong and Jinpumkong 2 soybean were found to be resistant to SDS as demonstrated by slight symptom with less than $20 \%$ foliage affected. The evaluation of SDS resistance could be beneficial to support varietal improvement through extensive soybean breeding program in Korea.
\end{abstract}

Keywords: Fusarium solani, soybean, sudden death syndrome

\section{INTRODUCTION}

Fusarium is a large genus encompassing a wide variety of fungal species. This genus is important to various industrial and agricultural sectors. Several members of the Fusarium species complex, such as Fusarium proliferatum, F. fujikuroi, $F$. verticillioides, F. equiseti, and F. solani (Marasas et al., 2006; Naim et al., 2008), may affect in diseases of several agricultural crops including rice, maize (Hsuan et al., 2011), and soybean (Aoki et al., 2012). F. solani was grouped into different formae specialis (f. sp.) and varieties (Nirenberg, 1995) based on host range. Using the sequences of $28 \mathrm{~S}$ rDNA, internal transcribed spacer (ITS) rDNA, and transcription elongation factor (TEF)- $1 \alpha$, molecular identification has shown that isolates from the $F$. solani species complex can be classified into 50 sub-specific lineages (O'Donnell, 2000). F. solani (Mart.) Sacc. (teleomorph: Nectria haematococca) (Berk. \& Br.), is considered to be an important phytopathogenic fungal agent of several crop diseases, such as root and fruit rot of Cucurbita spp., root and stem rot of pea, root rot of bean, and dry rot of potato, as well as sudden death syndrome (SDS) of soybean (Zaccardelli et al., 2008).

F. solani (Mart.) Sacc causing soybean SDS was recently described as $F$. solani f. sp. glycines to emphasize its host specialization (Aoki et al., 2003). Soybean SDS can be caused by diverse $F$. solani strains originating from different geographical regions and under different environmental conditions (Aoki et al., 2005; Swoboda, 2010). SDS is one of the major soil-borne disease that leads to significant yield losses. The severity of this disease depends on soybean cultivar susceptibility, cultural practices, and the presence of a conducive environment, such as cool/warm temperatures and high soil moisture (Roy et al., 1997). SDS which was first discovered in Arkansas in 1971, became wide spread in other states in the United States and in other regions of North and South America
(Rupe et al., 2001). Moreover, SDS has become one of the most important soybean diseases in the top ten world soybean producing areas (Mueller $\boldsymbol{e t} \boldsymbol{a l}$., 2002), such as the United States, Canada, Brazil, and Argentina (Wrather et al., 1997; Navi and Yang, 2008; Leandro et al., 2013).

$F$. solani infection begins at the roots of soybean plants and eventually, severe SDS leads to defoliation. The typical SDS symptoms include scattered and interveinal circular or irregular spots on leaves. In the foliar phase, some leaves prematurely turn yellow or brown, while some plants remain green and do not exhibit foliar symptoms (Hartman et al., 1997). With the development of SDS symptoms, all of the leaf tissue becomes chlorotic and necrotic, with a mottled, mosaic pattern on the upper leaves (Navi and Yang, 2008). Flower and young pod abortion can take place in severely infected plants. Other root symptoms, such as root rot and crown rot, develop during or before the appearance of prominent leaf symptoms. Internal and/or basal stem and tap root vascular tissues appear discolored and necrotic, which are obvious symptoms of SDS (Roy et al. 1997).

SDS evaluation protocols have been developed for leaf and stem symptom severity using stem inoculation and soil infestation techniques. Soybean cultivars are initially evaluated for resistance to $F$. solani in the field, then greenhouse and chamber experiments are conducted. A number of soybean cultivars have been screened for SDS resistance (Gray, 1996; Hartman et al., 1997; Navi and Yang, 2008; Aoki et al., 2012). Qualitative and quantitative resistance have been reported using United States Department of Agriculture (USDA) germplasm collections and variants of regenerated plants, but the majority of modern cultivars are considerably susceptible to SDS (Jin et $\boldsymbol{a l}$., 1996). The virulence ability of $F$. solani isolates causing soybean SDS varies (Li et al., 1999), and a 
preliminary report suggests the involvement of various races of $F$. solani in the severity of this disease (Mueller et al., 2002).

As current climate conditions change in Korea becoming more favorable for the development of SDS, isolating pathogenic $F$. solani and screening for soybean genotypes resistant to SDS are the first steps in a soybean breeding program aimed at controlling this disease. A number of indigenous $F$. solani strains from Korea was explored (Gopal $\boldsymbol{e t}$ al., 2012) but not for SDS evaluation purpose. Therefore, the present work was undertaken to isolate and identify Fusarium species based on morphological and molecular approaches using internal transcribed spacer (ITS) and transcription elongation factor (TEF)-1 $\alpha$, notably $F$. solani, from diseased soybean plants with SDS-like symptoms or root rot. In addition, we assessed the virulence of $F$. solani isolates against different soybean genotypes under artificially controlled conditions.

\section{MATERIAL AND METHODS}

\section{Collection and isolation of Fusarium species}

Soybean plants with SDS-like symptoms which were characterized by discolored stems and root rot, were collected at the R5 to R6 growth stages from two different fields, in Suwon (latitude: $37^{\circ} 17^{\prime} 27^{\prime \prime} \mathrm{N}$, longitude: $127^{\circ} 00^{\prime} 32^{\prime \prime} \mathrm{E}$ elevation above sea level:58 $\mathrm{m}$ ) and Daegu (latitude:35 52 ' $13^{\prime \prime} \mathrm{N}$, longitude: $128^{\circ} 35^{\prime} 27^{\prime \prime} \mathrm{E}$; elevation above sea level:45m), Korea, over a 3-year period, from 2009 to 2011. Both areas have similar long winter and high soil moisture. Suwon has the average rainfall of $1311 \mathrm{~mm}$, average annual temperature of $11.6{ }^{\circ} \mathrm{C}$, and minimum and maximum temperature of -5 to- $10{ }^{\circ} \mathrm{C}$ and around $30{ }^{\circ} \mathrm{C}$, respectively. While in Daegu, the average rainfall is $1055 \mathrm{~mm}$ and the average temperature is $13.6{ }^{\circ} \mathrm{C}$, the average minimum temperature is -2 to $-4{ }^{\circ} \mathrm{C}$ while maximum temperature is around $30{ }^{\circ} \mathrm{C}$. These fields experienced continuous soybean cultivation. Small pieces $(1-2 \times 1-2 \mathrm{~mm})$ of basal stems and roots were surface-sterilized in $1 \%$ sodium hypochlorite and rinsed in sterile water. The tissue sections were then air-dried on filter paper and plated onto potato dextrose agar (PDA) medium supplemented with $500 \mathrm{mg} / \mathrm{L}$ streptomycin to suppress bacterial growth. The culture plates were incubated at $25^{\circ} \mathrm{C}$ under a $12 \mathrm{~h}$ light/dark regime. The obtained isolates were purified by sub-culturing single spores, and the pure fungal isolates were stored in $30 \%$ glycerol at $-80{ }^{\circ} \mathrm{C}$ until use.

\section{Molecular and morphological characterization of $\boldsymbol{F}$. solani}

For genomic DNA isolation, each fungal strain was grown in liquid complete medium $(\mathrm{CM})$ at $25{ }^{\circ} \mathrm{C}$ on a rotary shaker $(150 \mathrm{rpm})$ for 3 days, and the mycelial mass was harvested and lyophilized. DNA was extracted with a cetyltrimethylammonium bromide protocol (Leslie and Summerell, 2006). All fungal isolates were first observed their macroscopic morphology. These isolates were then identified based on their sequences of internal transcribed spacer (ITS) region of ribosomal DNA amplified and sequenced with an ITS primer pair, ITS4 (5'-TCC TCC GCT TAT TGA TAT GC-3') and ITS5 (5'-GGA AGT AAA AGT CGT AAC AAG G-3') (White et al., 1990). F. solani species were further characterized by using DNA sequences of partial translation elongation factor (TEF)- $1 \alpha$ amplified with specific primers ef1 (forward primer; 5'-ATG GGT AAG GA(A/G) GAC AAG AC-3) and ef2 (reverse primer; 5'-GGA (G/A)GT ACC AGT (G/C)AT CAT GTT-3' (O'Donnell et al., 1998). Oligonucleotides were synthesized by the Bioneer oligonucleotide synthesis facility (Daejon, South Korea). The amplified PCR product showing a single band on agarose gel electrophoresis was purified and used as a template for sequencing using a BigDye Terminator Cycle Sequencing Kit V.3.1 (Applied Biosystems, Foster City, CA, USA). Sequence analysis was performed with an automatic sequencer, Model ABI 3730 (Applied Biosystems) and the resulting sequences were analyzed using SeqScape software v. 2.0 (Applied Biosystems). For homology analysis, the sequences were compared against the non-redundant sequence data using BLAST. Sequences of several Fusarium species in the public database were included for phylogenetic tree construction. A neighbor-joining (NJ) tree was constructed with MEGA 4.0 using the bootstrap method with 1,000 replications (Tamura et al., 2007).

The morphological differences among the fungal isolates of F.solani were characterized by examining several parameters (colony, conidia and conidiophores, perithecia, and chlamydospores). Fungal isolates were grown on PDA for 8 days to observe fungal colony. Morphology of conidia, conidiophores, chlamydospore, and perithecia was observed from 6-14-day-old carnation leafpiece agar (CLA) cultures (Leslie and Summerell, 2006). CLA cultures were incubated at $25{ }^{\circ} \mathrm{C}$ under near UV light (wavelength: $365 \mathrm{~nm}$; HKiv Import \& Export Co., Ltd., Xiamen, China) to induce asexual and sexual reproduction. Differential interference contrast (DIC) images were obtained with a DE/Axio Imager A1 microscope (Carl Zeiss, Oberkochen, Germany).

\section{Evaluation of SDS susceptibility}

Five soybean genotypes that have been primarily used as parents for genetic mapping populations were selected for pathogenicity testing using nine $F$. solani isolates. In addition to the five genotypes, four genotypes of a USDA germplasm collection including SDS-resistant genotype (PI 536636: Ripley), SDSsusceptible genotype (PI 652935: BARC-19), as well as Haiiro (PI 243530) and Spencer (PI 525454) were also included against three selected $F$. solani isolates (SSLP2, 20, and 22).

F. solani isolates were grown at $25{ }^{\circ} \mathrm{C}$ for 7 days and used to infest red sorghum seeds that had been soaked overnight and autoclaved twice. Five plugs ( $4 \mathrm{~mm}$ in diameter) of mycelia were used for inoculation. The seeds were incubated with the mycelia at $24{ }^{\circ} \mathrm{C}$ for 2 weeks. A mixture of sterilized fertilizer:soil (1:1) was placed into $10 \times 10 \times 10 \mathrm{~cm}^{3}$ tubes. The drain hole of each tube was plugged with non-absorbent cotton, the tube was prefilled with sterile soil mixture, and $7 \mathrm{~g}$ of infected sorghum seeds were evenly distributed onto the soil mixture. Additional soil mixture was added to each tube, directly covering the infected seeds, at a depth of $2 \mathrm{~cm}$. Soybean seeds were planted in the soil mixture, and the seeds were covered with additional soil mixture. Non-inoculated red sorghum seeds were used as a control. A pathogenicity test was conducted in a growth chamber programmed for $12 \mathrm{~h}$ day/night, a temperature of $25^{\circ} \mathrm{C}$, and a relative humidity of $80 \%$, with three replications per treatment. After seedling emergence, the soil moisture was maintained near water holding capacity. Four weeks after planting, each plant was evaluated for SDS leaf symptoms using disease rating according to standard criteria (Hartman et al., 1997). The criteria were determined as follows: 1 = no symptoms (high resistant), 2 = slight symptom showing 1 to $20 \%$ foliage affected (resistant), $3=21$ to $50 \%$ foliage affected (moderate), $4=$ heavy symptom with 51 to $80 \%$ foliage affected (susceptible), and $5=$ severe symptom showing 81 to $100 \%$ foliage affected (high susceptible).

\section{Colonization of $F$. solani in soybean}

The stems and roots of $F$. solani-inoculated plants showing SDS symptoms were collected 4 weeks after planting for observation via microscopy. The plants were rinsed in running tap water and prepared for microtome sectioning. Both $F$. solani-inoculated and control samples were fixed with modified Karnovsky's fixative solution ( $2 \%$ paraformaldehyde supplemented with $2 \%$ glutaraldehyde in $0.05 \mathrm{~mol} / \mathrm{L}$ sodium cacodylate buffer) and washed in $0.05 \mathrm{~mol} / \mathrm{L}$ sodium cacodylate buffer. The samples were then post-fixed in $1 \%$ osmium tetroxide in $0.05 \mathrm{~mol} / \mathrm{L}$ sodium cacodylate buffer and briefly washed twice in distilled water. The tissues were infiltrated with stain and embedded overnight by en bloc staining with $0.5 \%$ uranyl acetate at $4{ }^{\circ} \mathrm{C}$. After the samples were dehydrated in a graded ethanol series and propylene oxide and embedded in Spurr's resin, they were polymerized at $70{ }^{\circ} \mathrm{C}$ for $24 \mathrm{~h}$. Thick sections were generated with an ultra microtome and observed by light microscopy.

\section{Statistical analysis}

All data were subject to analysis of variance (ANOVA) using SAS software (SAS, Cary, NC, USA). The statistical difference in infection rate was tested by the least significant differences (LSD) at $P \leq 0.05$ (SAS, 2002).

\section{RESULTS}

\section{Isolation of $\boldsymbol{F}$. solani}

All fungal colonies grew rapidly $( \pm 9 \mathrm{~cm}$ in diameter) at room temperature, and macroconidia appeared one week after inoculation. Most isolates produced Fusarium-shaped conidia and possessed cottony aerial mycelia with various color from whitish, yellowish-white or pale to yellow, brownish, pinky to bluish, sometimes with purple were observed. A comparison of the genomic sequences of the ITS regions revealed that all isolates shared high sequence homology with known Fusarium species at a level ranging from 99 to $100 \%$ (Table 1). Of the 54 isolates examined, nine isolates were identified as Fusarium solani, and the rest were $F$. equiseti (31 isolates), Gibberella moniliformis (anamorph: $F$. verticillioides; 13 isolates), and Gibberella zeae (anamorph: F. graminearum Schwabe; one isolate). All $F$. solani were further characterized their molecular and morphological properties.

\section{Molecular and morphological characterization of $F$. solani}

TEF sequences of nine $F$. solani isolates (SSLP2, 14, 15, 16, 17, 18, 19, 20, and 22 ) with other Nectria haematococca- $F$. solani species isolated from various hosts were used for the phylogenetic analysis (O'Donnell, 2000). All of the strains identified in this study were included in the clade 3 which contained Asian F. solani species (Fig. 1). Five isolates (SSLP14, 15, 16, 19, and 20) were grouped with $F$. solani f. sp. pisi strains. SSLP2/22 and SSLP18 strains were similar in TEF sequences with $F$. solani strains causing human eye keratitis at USA and India, respectively (O'Donnell $\boldsymbol{e t}$ al., 2007). SSLP17 was out grouped with Neocosmospora africana (another sexual stage name of $F$. solani) which was isolated from South African soil (O'Donnell, 2000). Based on the virulence level category, isolates with high virulence especially SSLP15, 14 and 20 tend to be the same subclade indicating their close genetic relationship to support their same environment in Daegu where this site is more favorable for SDS than 
Suwon. While isolates having lower virulence seemed to distribute in several branches.

Fungal characters on PDA vary depending on strains (Fig. 2). Cultures of SSLP14/15/20, SSLP16/19, and SSLP18 strains were white to creamy with sparse mycelium, which is typical for most $F$. solani species (Leslie and Summerell, 2006). SSLP17 strain grew very slowly compared to other strains, and both SSLP2 and 22 produced violet pigments with fluffier aerial mycelium (Fig. 2)

$F$. solani produced asexual spores in the form of macroconidia and microconidia Macroconidia were faintly curved with a notched basal cell of $F$. solani which usually produces 3- to 7-septate macroconidia and 0- or 2-septate microconidia (Leslie and Summerell, 2006). In our study, however, few microconidia were seen in among $F$. solani isolates. Cream sporodochia, lumps of macroconidium, were common on carnation leaf pieces in all of the $F$. solani strains and microconidia were observed on remained agar surface of CLA medium (Fig. 3A) Seven strains (SSLP14, 15, 16, 17, 18, 19, and 20) produced typically shaped macroconidia (Fig. 3B), phialide (Fig. 3C), and microconidia (Fig. 3D) for $F$ solani. However, SSLP2 and 22 strains generated relatively longer macroconidia (Fig. 3E) and shorter microconidia (Fig. 3G) compared to other strains, whereas morphology of phialides was indistinguishable (Fig. 3F). Typica chlamydospores were observed in cultures of all of the tested strains (Fig. $3 \mathrm{H}$ ) Only three $F$. solani strains (SSLP2, 17, and 22) produced red/orange perithecia (Fig. 3I) which contain rosette asci (Fig. 3J). In particular, SSLP17 strain produced more perithecia and fewer conidia compared to other strains.

\section{Pathogenicity of F.solan}

All F. solani isolates were examined for their virulence on various soybean genotypes. The isolates produced various levels of typical SDS symptoms, such as interveinal chlorosis and necrosis on young leaves, when inoculated on soybean plants grown in a growth chamber. Typical SDS symptoms were observed on soybean leaflets and roots. Notably, the F.solani pathogen was reisolated from surrounding area of the infected soybean plants and identified as the same species, demonstrating Koch's postulated.

After inoculation with the isolates SSLP2, SSLP20, and SSLP22, SDS-resistan 'Ripley' showed an average SDS severity value of $0.03 \%$, while a value of $21.9 \%$ was observed in SDS-susceptible 'BARC-19' which was comparable with'Spencer' $(21.4 \%)$. None of the tested soybean genotypes exhibited lower values of SDS severity than Ripley or higher values than BARC-19, which was especially high when the later genotype was infected with SSLP22 (48.23\%). Even though a bit less, this severity rating using SSLP22 indigenous from Korea is in good agreement with the USDA examination that BARC has been categorized as susceptible genotype. Haiiro' considerably exhibited resistance to SDS, with mean severity value of $12.2 \%$ against the three isolates, respectively (Table 2). This result suggests that different geographical and environmental conditions contribute the distinct virulence of $F$. solani strains.

The average SDS severity of Korean soybean genotypes was examined in plants grown in a growth chamber 4 weeks after inoculation with $F$. solani (Table 3 ). The main effect that showed significant differences was the percent of leaflets with SDS symptoms $(P<0.05)$, which depended on the fungal isolate used for inoculation. SSLP15 showed the greatest pathogenicity, with levels of $24.0 \%$ whereas SSLP17 had the lowest pathogenicity at only $1.3 \%$. Moreover, the virulence levels of selected isolates which were surveyed against the USDA genotypes and Korean genotypes were relatively comparable levels (Table 2 and Table 3). Highly significant soybean genotype effects were also detected ( $P$ 0.05 ) in terms of disease severity. Danbaekkong and Jinpumkong 2 showed the lowest SDS severity (7.9\%), while Pureunkong had the highest SDS severity (15.0\%; Table 3). Significant interaction effects were also observed between isolates and soybean genotypes $(P<0.05)$. Pureunkong infected with SSLP15 exhibited the most severe SDS symptoms on leaflets $(46.3 \%)$. In addition to Pureunkong, SSLP15 had the strongest virulence when Taekwangkong was infected, and Jinpumkong 2 was more severely infected by SSLP20. These results suggest that the host plant genotype affects the response of symptomatic leaflets to inoculation with $F$. solani

\section{$F$. solani colonization in soybean roots}

In the current study, colonization of $F$. solani was observed in host plants exhibiting SDS symptoms. No hyphae were observed in non-inoculated or healthy plants suggesting no colonization of fungus in the plant tissue. But infected plants had external and internal discoloration of basal stems and taproots, representing SDS symptoms (Fig. 4) as the effect of F. solani. Hyphae were detected in both phloem (Fig. 4A) and xylem tissues (Fig. 4B) of discolored basal stems and roots, causing foliar-like SDS symptoms. We determined that xylem tissues were more effective as $F$. solani colonization zones than phloem (Fig. 4C), and xylem colonization contributed to foliar symptoms to a greater extent than phloem colonization, which supports observations of a previous study (Navi and Yang, 2008).
Table 1 List of Fusarium spp. isolates

\begin{tabular}{|c|c|c|c|c|}
\hline Isolates & Species & Location & $\begin{array}{c}\text { Year } \\
\text { isolated }\end{array}$ & $\begin{array}{c}\text { Homology (E- } \\
\text { value) }\end{array}$ \\
\hline SSLP1 & Fusarium equiseti & Daegu & 2010 & $100(0)$ \\
\hline SSLP2 & F. solani & Daegu & 2010 & $99(0)$ \\
\hline SSLP3 & F. equiseti & Suwon & 2011 & $100(0)$ \\
\hline SSLP8 & F. equiseti & Suwon & 2009 & $100(0)$ \\
\hline SSLP10 & $\begin{array}{l}\text { Gibberella } \\
\text { moniliformis }\end{array}$ & Suwon & 2009 & $100(0)$ \\
\hline SSLP11 & F. equiseti & Suwon & 2009 & $100(0)$ \\
\hline SSLP14 & F. solani f. sp. pisi & Daegu & 2010 & $100(0)$ \\
\hline SSLP15 & F. solani f. sp. pisi & Daegu & 2010 & $100(0)$ \\
\hline SSLP16 & F. solani f. sp. pisi & Daegu & 2010 & $100(0)$ \\
\hline SSLP17 & $\begin{array}{l}\text { Neocosmospora } \\
\text { african }\end{array}$ & Daegu & 2010 & $100(0)$ \\
\hline SSLP18 & $F$. solani & Daegu & 2010 & $100(0)$ \\
\hline SSLP19 & F. solani f. sp. pisi & Daegu & 2010 & $100(0)$ \\
\hline SSLP20 & F. solani f. sp. pisi & Daegu & 2010 & $100(0)$ \\
\hline SSLP22 & F. solani & Daegu & 2010 & $100(0)$ \\
\hline SSLP28 & G. moniliformis & Suwon & 2010 & $99(0)$ \\
\hline SSLP29 & G. moniliformis & Suwon & 2010 & $100(0)$ \\
\hline SSLP30 & G. moniliformis & Suwon & 2010 & $100(0)$ \\
\hline SSLP31 & F. equiseti & Suwon & 2010 & $100(0)$ \\
\hline SSLP32 & F. equiseti & Suwon & 2010 & $100(0)$ \\
\hline SSLP33 & F. equiseti & Suwon & 2010 & $100(0)$ \\
\hline SSLP34 & F. equiseti & Daegu & 2010 & $100(0)$ \\
\hline SSLP35 & F. equiseti & Daegu & 2010 & $99(0)$ \\
\hline SSLP36 & G. moniliformis & Daegu & 2010 & $100(0)$ \\
\hline SSLP37 & G. moniliformis & Daegu & 2010 & $100(0)$ \\
\hline SSLP38 & F. equiseti & Suwon & 2010 & $100(0)$ \\
\hline SSLP39 & F. equiseti & Suwon & 2010 & $100(0)$ \\
\hline SSLP40 & F. equiseti & Daegu & 2010 & $100(0)$ \\
\hline SSLP41 & F. equiseti & Daegu & 2010 & $100(0)$ \\
\hline SSLP42 & F. equiseti & Daegu & 2010 & $100(0)$ \\
\hline SSLP43 & F. equiseti & Suwon & 2009 & $100(0)$ \\
\hline SSLP44 & F. equiseti & Suwon & 2009 & $100(0)$ \\
\hline SSLP45 & F. equiseti & Suwon & 2009 & $100(0)$ \\
\hline SSLP46 & F. equiseti & Suwon & 2009 & $100(0)$ \\
\hline SSLP47 & F. equiseti & Suwon & 2011 & $100(0)$ \\
\hline SSLP49 & G. moniliformis & Suwon & 2011 & $100(0)$ \\
\hline SSLP50 & G. moniliformis & Suwon & 2011 & $100(0)$ \\
\hline SSLP51 & G. moniliformis & Suwon & 2011 & $100(0)$ \\
\hline SSLP52 & G. moniliformis & Suwon & 2011 & $100(0)$ \\
\hline SSLP53 & G. moniliformis & Suwon & 2011 & $100(0)$ \\
\hline SSLP54 & G. moniliformis & Suwon & 2011 & $100(0)$ \\
\hline SSLP55 & G. moniliformis & Suwon & 2011 & $100(0)$ \\
\hline SSLP56 & F. equiseti & Suwon & 2011 & $99(0)$ \\
\hline SSLP58 & F. equiseti & Suwon & 2011 & $100(0)$ \\
\hline SSLP60 & F. equiseti & Suwon & 2011 & $100(0)$ \\
\hline SSLP61 & F. equiseti & Suwon & 2011 & $100(0)$ \\
\hline SSLP62 & F. equiseti & Suwon & 2011 & $100(0)$ \\
\hline SSLP63 & F. equiseti & Suwon & 2011 & $100(0)$ \\
\hline SSLP64 & F. equiseti & Suwon & 2011 & $100(0)$ \\
\hline SSLP67 & G. zeae & Suwon & 2011 & $100(0)$ \\
\hline SSLP68 & F. equiseti & Suwon & 2011 & $100(0)$ \\
\hline SSLP69 & F. equiseti & Suwon & 2011 & $99(0)$ \\
\hline SSLP71 & F. equiseti & Suwon & 2011 & $100(0)$ \\
\hline SSLP74 & F. equiseti & Suwon & 2011 & $100(0)$ \\
\hline SSLP75 & F. equiseti & Suwon & 2011 & $100(0)$ \\
\hline
\end{tabular}

Fusarium solani species and its asexual stage are denoted in bold letters

Table 2 Mean SDS severity values for USDA soybean genotypes 4 weeks after inoculation with $F$. solani isolates (SSLP2, 20, 22)

\begin{tabular}{lccccc}
\hline \multirow{2}{*}{ Isolates } & \multicolumn{4}{c}{ Soybean genotypes } & \multirow{2}{*}{ Mean* } \\
\cline { 2 - 4 } & BARC-19 & Ripley & Spencer & Haiiro & \\
\hline SSLP2 & 8.18 & 0 & 9.81 & 5.20 & $5.80^{\mathrm{c}}$ \\
SSLP20 & 9.18 & 0 & 42.22 & 9.26 & $15.16^{\mathrm{b}}$ \\
SSLP22 & 48.23 & 0.10 & 12.21 & 22.07 & $20.65^{\mathrm{a}}$ \\
Mean* & $21.9^{\mathrm{a}}$ & $0.03^{\mathrm{d}}$ & $21.4^{\mathrm{b}}$ & $12.2^{\mathrm{c}}$ & \\
\hline
\end{tabular}

*Within fungal inoculum and host soybean genotype combinations, means in column followed by the same letter are not significantly different at $\mathrm{P}<0.05$ based on LSD

**Categories of SDSseveriy rating: $1=$ no symptoms (high resistant), $2=$ slight symptom showing 1 to $20 \%$ foliage affected (resistant), $3=21$ to $50 \%$ foliage affected (moderate), $4=$ heavy symptom with 51 to $80 \%$ foliage affected (susceptible), and $5=$ severe symptom showing 81 to $100 \%$ foliage affected (high susceptible) 
Table 3 SDS severity of host soybean plant genotypes against $F$. solani isolates

\begin{tabular}{|c|c|c|c|c|c|c|}
\hline \multirow[t]{2}{*}{ Isolates } & \multicolumn{5}{|c|}{ Soybean genotypes } & \multirow[b]{2}{*}{ Mean* } \\
\hline & Danbaekkong & Pureunkong & Taekwangkong & SS2-2 & Jinpumkong 2 & \\
\hline & \multicolumn{6}{|c|}{ Severity rating $(\%)^{* *}$} \\
\hline SSLP2 & 13.2 & 5.5 & 5.2 & 3.2 & 6.2 & $6.6^{\mathrm{cd}}$ \\
\hline SSLP14 & 5.4 & 43.4 & 14.3 & 26.4 & 5.0 & $18.9^{\mathrm{ab}}$ \\
\hline SSLP15 & 1.2 & 46.3 & 36.0 & 23.4 & 13.2 & $24.0^{\mathrm{a}}$ \\
\hline SSLP16 & 12.6 & 18.4 & 0.5 & 9.5 & 0.8 & $8.3^{\mathrm{c}}$ \\
\hline SSLP17 & 0.7 & 4.1 & 1.1 & 0.5 & 0.2 & $1.3^{\mathrm{d}}$ \\
\hline SSLP18 & 8.1 & 5.5 & 26.3 & 0.5 & 0.2 & $8.1^{\mathrm{c}}$ \\
\hline SSLP19 & 0.3 & 19.3 & 11.3 & 0.7 & 0.7 & $6.4^{\mathrm{cd}}$ \\
\hline SSLP20 & 8.2 & 15.4 & 5.2 & 23.4 & 34.3 & $17.3^{\mathrm{b}}$ \\
\hline SSLP22 & 21.8 & 10.2 & 5.6 & 8.2 & 10.3 & $11.2^{\mathrm{c}}$ \\
\hline Mean* & $7.9^{c}$ & $15.0^{\mathrm{a}}$ & $11.7^{\mathrm{b}}$ & $10.6^{\mathrm{ab}}$ & $7.9^{c}$ & \\
\hline
\end{tabular}

*Within fungal inoculum and host soybean genotype combinations, means (column or row) not followed by the same letter are significantly different at $P \leq 0.05$ based on

LSD, **The categories of SDS severity rating are the same as those on Table 2

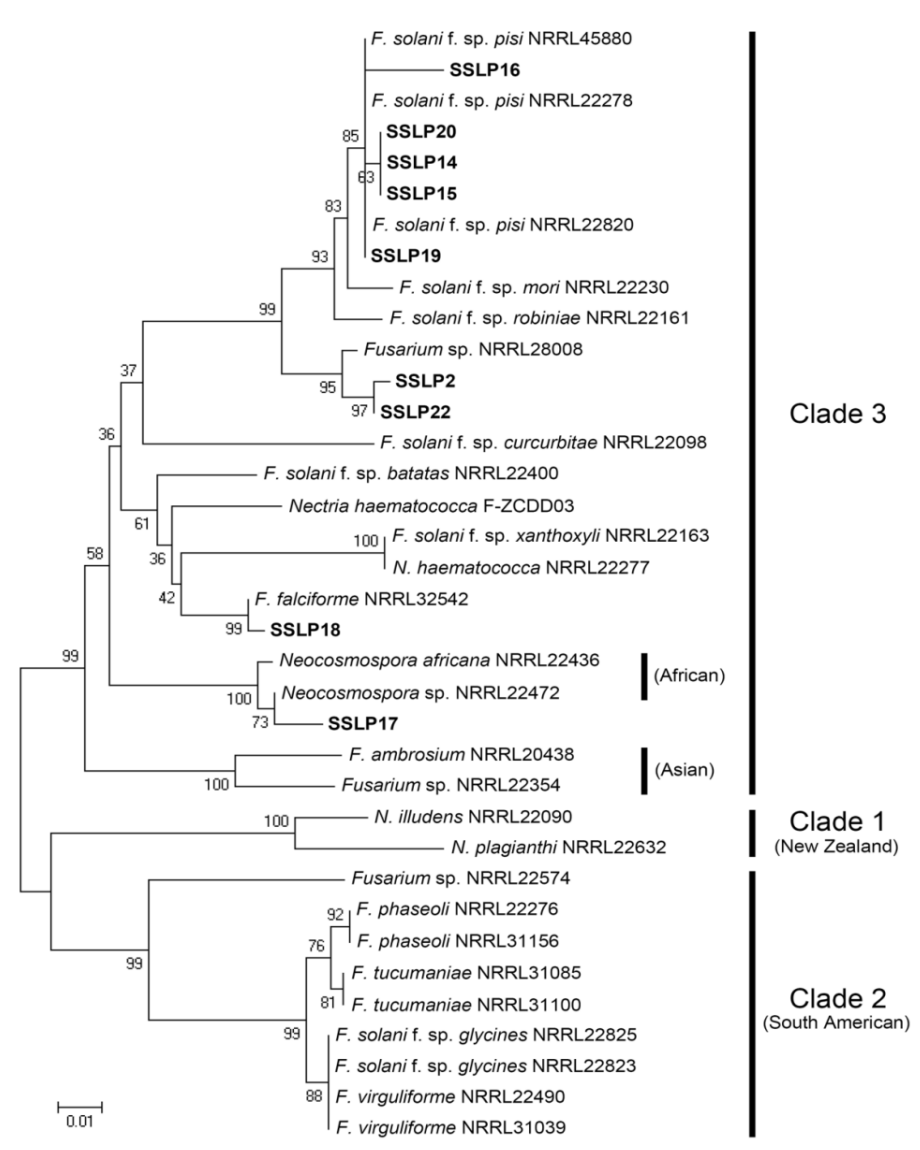

Figure 1 Phylogenetic tree of $F$. solani species complex produced by examining the sequence homology of the partial translation elongation factor (TEF)-1 $\alpha$ using the neighbor-joining method with bootstrap values from 1000 replications

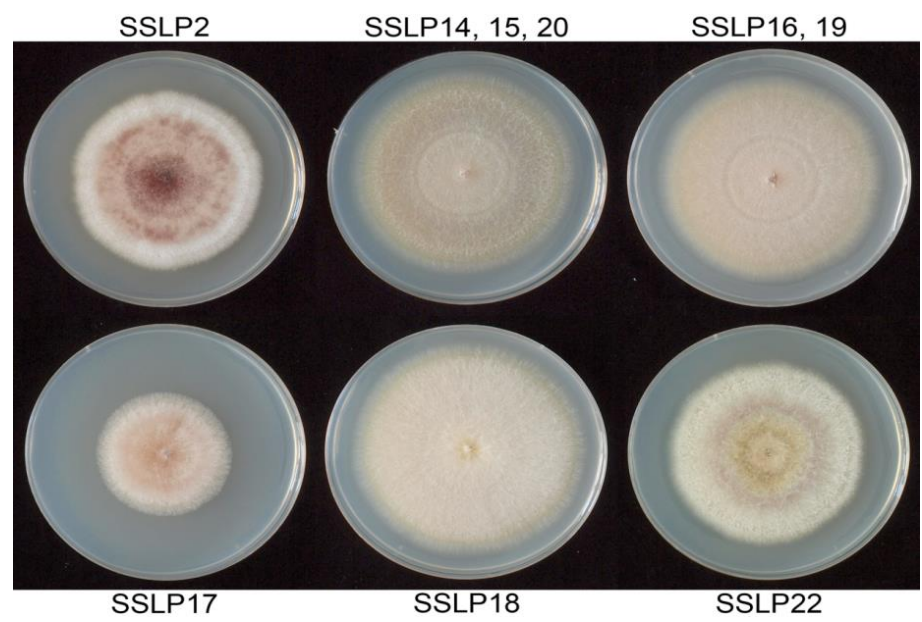

Figure 2 Mycelial growth of $F$. solani strains on potato dextrose agar (PDA) incubated at $25^{\circ} \mathrm{C}$. Pictures were taken 8 days after inoculation on PDA
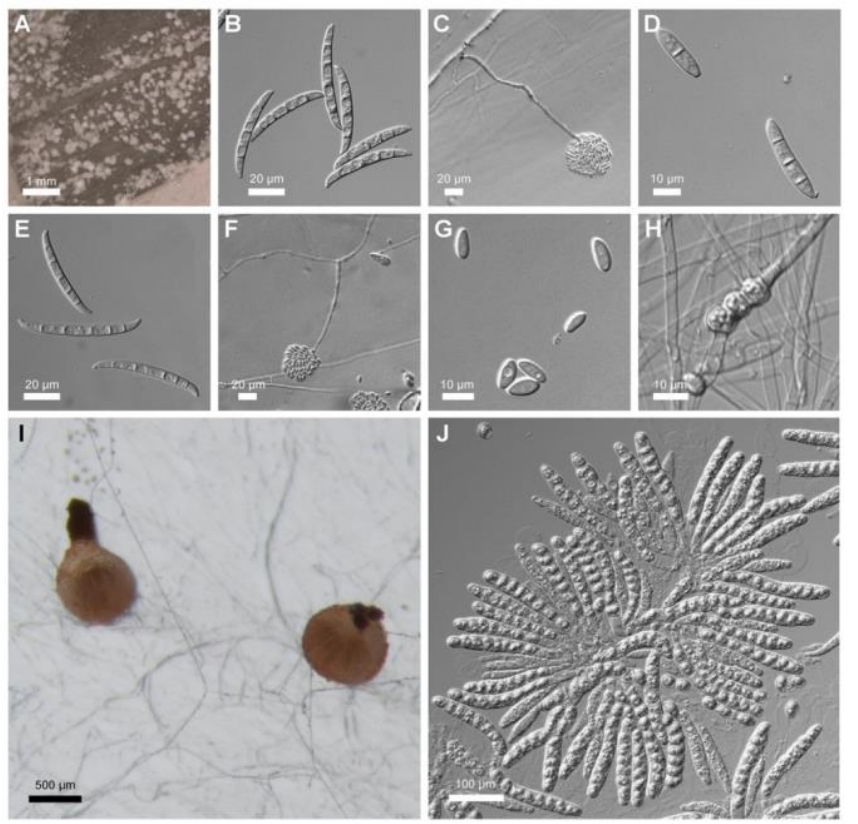

Figure 3 Morphological characters of $F$. solani strains. A, sporodochia produced on carnation leaf pieces. Macroconidia $(\mathbf{B})$, phialide $(\mathbf{C})$, and microconidia $(\mathbf{D})$ produced by SSLP14, 15, 16, 17, 18, 19, or 20 strains. Macroconidia (E), phialide $(\mathbf{F})$, and microconidia $(\mathbf{G})$ produced by SSLP2 or 22 strains. $\mathbf{H}$ chlamydospores produced by $F$. solani strains. I, red/orange perithecia produced by SSLP2, 17, or 22 strains. J, rosette asci dissected from perithecia. Pictures were taken 6-14 days after inoculation on carnation leaf agar (CLA) cultures

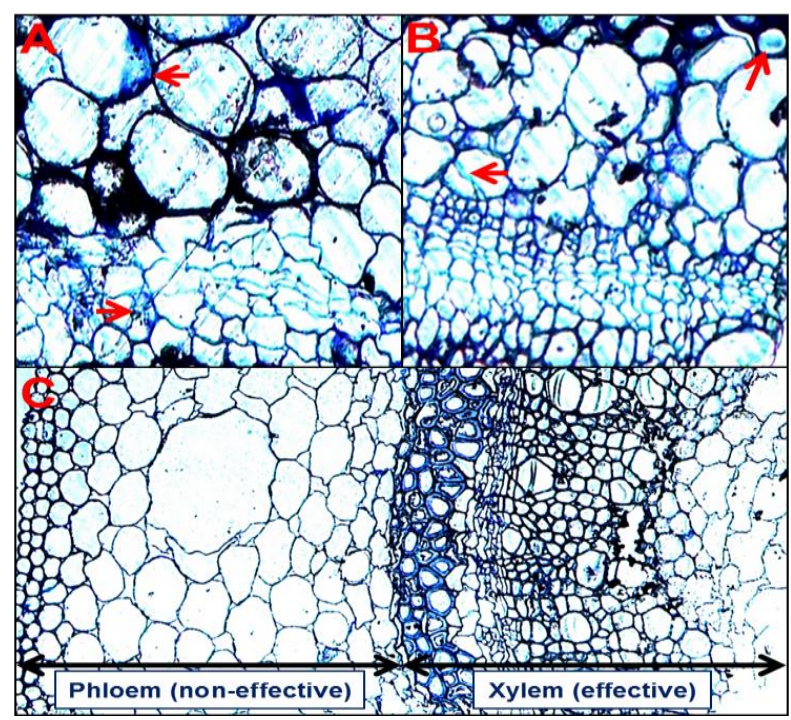

Figure 4 Colonization of $F$. solani hyphae in cross sections of tissue from a soybean plant with foliar, basal stem, and root symptoms of SDS. A, F. solani hyphae in phloem tissue. B, F. solani hyphae in xylem tissue. C, Colonization of $F$. solani in effective and non-effective zones in the xylem and phloem tissues of soybean, respectively 


\section{DISCUSSION}

Sudden death syndrome (SDS) is thought to be optimal in favored high soil moisture and low temperature during the early growing season of soybean followed by relatively high temperature. Longer winter and higher rainfall with hot climate during summer seem to attribute the occurrence of SDS and root rot symptom soybean crop in Korea recently. As demonstrated in this current study, during 2009-2011, SDS-like symptom with root rot was observed in some fields of cultivated soybean in Korea, leading to isolate the fungal pathogen.

We identified predominant species of Fusarium, especially $F$. solani, F. equiseti, G. moniliformis, F. solani, and G. Zeae based on molecular and morphological approaches. Morphological observation is helpful to identify this Fusarium species because literally, the morphological characteristics assisted to initially differentiate fungal species even though easy misidentification usually occurred Morphological identification of Fusarium species (Marasas et al., 2001; Hsuan 2011) is able to sort important species especially $F$. solani group before employing another method (Leslie and Summerell, 2006) or molecular approach. In particular, the identified $F$. solani from SDS-diseased soybean plants agreed with previous studies that this fungus causes soybean SDS. These suggest that cool soil temperatures and higher humidity levels during the 3-year sampling period, have a favorable environment for SDS pathogen development Moreover, these fields contain historical hot spots for soybean diseases, with continuous soybean planting. This condition can be more severe since some plant-parasitic nematodes are interacted with SDS development (Xing and Westphal, 2013), however, $F$. solani was also reported to be pathogenic to the nematode eggs of Heterodera. glycines (McLean and Lawrence, 1995). In addition, $F$. equiseti and $G$. moniliformis species complex are the most common diseases reported in agricultural crops worldwide, including soybean (Jasnic $\boldsymbol{e}$ al., 2005; Hsuan et al., 2011). Recently, F. graminearum was also reported to be pathogenic and a causal agent of SDS in cereal crops as well as soybean (Martinelli et al., 2004; Brar et al., 2011).

Based on the criterion of the morphology of microconidia produced on the conidiophore and macroconidia formed on sporodochia, nine $F$. solani in our study showed typical characters (Fig. 3). These morphological characteristics could be a basic information to classification into formae specialis of fungal isolates. Morphological characters of some isolates were matched with F. solan f. sp. pisi described previously (Jung et al., 1999). These initial morphological characters are very potential for genetic studies on the molecular basis of pathogenicity. Moreover, part of ascospore could be seen clearly among isolates, might be responsible for their survival as shown by their morphological structure. Phylogenetic tree analysis revealed that a variety of soybean SDS-causing $F$ solani strains were found in Korea. All isolates seem genetically closer to the $F$. solani from Asia than other continents. This SDS agent, F. solani isolates from Korea could be specific because they had far distance with F. solani species complex, such as $F$. tucumaniae and $F$. virguliforme from South America which are well known as SDS agent as well. A number of isolates (SSLP14, 15, 16, 19 and 20) which belong to $F$. solani f. sp. pisi suggests that the habitat of this species varies, not only pea, ginseng, mulberry, chickpea (Matuo and Snyder, 1973) but also soybean. As supported by a prior study that $F$. solani f. sp. pisi was also found on soybean and showed remarkable virulence in pea seedling (Jung et al., 1999). Another finding showing one of a sexual stage of $F$. solani, Neocosmospora africana (SSLP17) was also demonstrated. These asexual and sexual behaviors may be useful for deeper identification of formae speciales and races of these pathogens. While, some isolates (SSLP2/22 and SSLP18) similar to $F$. solani causing human eye keratitis indicate that the results are consisten with a claim that some $F$. solani species shares pathogenicity both on humans and plants (Zhang et al., 2006). Even though human eye keratitis caused by $F$. solan can be established fairly slow, but this could progress rapidly (Wu et al., 2004) Further studies should be conducted to these particular isolates to investigate fusarial keratitis infection on eye using mice model.

To help elucidate the mechanism of root infection by $F$. solani, it is important to relate aboveground symptoms to root colonization (Navi and Yang, 2008) Damaged tissues and discolored basal stems and taproots have hyphae in their xylem and phloem, indicating that infection of $F$. solani in root tissues causes the occurrence of foliar SDS symptoms. This result is in good agreement with the results of a previous study, which demonstrated that superficial colonization on taproots outside of the xylem produces fewer foliar symptoms than infection that occurs later in the growth stage (Yang and Navi, 2003). Moreover, early infection at the seedling stage enables the effective development of SDS fungi in xylem tissues, leading to foliar SDS symptoms (Gao et al. 2006). The current study demonstrates that the presence of SDS fungi in root tissues is associated with foliar symptoms, which supports a previous study showing a strong association between foliar expression of SDS and the incidence of root colonization (Luo et al., 1999). These foliar symptoms are predicted to be induced by a specific toxin(s) from $F$. solani (Navi and Yang, 2008; Brar et al. 2011) such as an acidic protein named FvTox1 which has been hypothesized to interfere with photosynthesis and causes foliar SDS. The way of penetration of fungi into plant tissue with its specific toxin movement may give a clue to the mechanism involved in the soybean host-pathogen interaction (Pudake $\boldsymbol{e t}$ al. 2013).
F. solani can survive for several years by introducing its spores and mycelium into the soil and into soybean plants (Aoki et al., 2003). An SDS outbreak may occur after fungal mycelia become established and well-adapted to a new, favorable environment (Malvic and Bussey, 2008). In Korea, the soybean SDS occurrence has been increasingly surveyed, however, no studies prioritize the SDS evaluation. F. solani isolates were only found in Daegu, indicating that Daegu located in "basin" region with cool soil temperature and higher humidity gives a favorable environment for SDS pathogen development. The Daegu fields having a historical hot spot of soybean diseases with continuous soybean planting during several years were preferentially targeted for sample collection. As a result, fungi isolated from plants was affected by the nature of the diseased tissues. In this regard, geographical range is a critical factor to understand SDS and contributes a risk of soybean production in a region (Malvic and Bussey, 2008). Therefore, in soybean breeding programs, it is important to identify $F$. solani isolates with high pathogenicity and host plant genotypes with strong SDS resistance. In this study, the $F$. solani isolates SSLP15 showed the greates virulence. These selected indigenous $F$. solani isolates having high pathogenicity may represent important fungal pathogen resources that can be used in the evaluation of soybean genotypes resistant to SDS in Korea. In addition to their pathogenicity assay, the examination of the $F$. solani population being as interaction or individual depending on species could be beneficial methods in SDS control management (Marburger et al., 2014).

Resistant varieties are one of the way to reduce the risk of yield losses due to SDS (Leandro, et al., 2013), thus it is necessary to incorporate SDS resistance into future soybean cultivars with increased yields (Brzostowski et al., 2014; Adee, 2015). In this study, we observed differential reactions of host soybean plant genotypes to $F$. solani isolates (Table 3 ). We selected five Korean soybean elite cultivars showing insect resistance (Li et $\boldsymbol{a l}$., 2008) and mostly used as mapping parents to support a good genetic material for pathogenicity test. None of the soybean genotypes showed high resistance to all $F$. solani isolates examined. However, Danbaekkong and Jinpumkong 2 were moderate resistant only to SSLP22 and SSLP20, respectively, and overall these genotypes exhibited resistance to SDS. Thus, Danbaekkong and Jinpumkong 2 may represent a good source of SDS resistance in addition to Ripley, which possess a single gene for resistance to $F$. solani based on the severity of leaf symptoms (Gray, 1996).

\section{CONCLUSION}

The characterized $F$. solani isolates showed their potency according to the pathogenicity and the highest pathogenic strain (SSLP15) could be useful to assist in the evaluation of soybean resistance to SDS. The selected genotypes resistant to SDS (Danbaekkong and Jinpumkong 2) could be used as resistance check/control for further screening of soybean genotypes for SDS resistance and genetic mapping of genes for SDS resistance which will be needed to successfully breed soybean using the virulent $F$. solani strains isolated in this study.

Acknowledgments: This research was supported by a grant from the NextGeneration BioGreen 21 Program (No. PJ008117) of the Rural Development Administration, Republic of Korea.

\section{REFERENCES}

Adee, E. A. 2015. Effects of Seed Treatment on Sudden Death Syndrome Symptoms and Soybean Yield," Kansas Agricultural Experiment Station Research Reports: Vol. 1: Iss. 2.

Aoki, T., O'Donnell, K., Yoshihisa H, Lattanzi, A.R. 2003. Sudden-death syndrome of soybean is caused by two morphologically and phylogenetically distinct species within the Fusarium solani species complex-F. virguliforme in North America and F. tucumaniae in South America. Mycologia, 95, 660 684.http://dx.doi.org/10.2307/3761942

Aoki, T., O'Donnell, K., Scandiani, M. M. 2005. Sudden death syndrome of soybean in South America is caused by four species of Fusarium: Fusarium brasiliense sp. nov., F. cuneirostrum sp. nov., $F$. tucumaniae, and $F$. virguliforme. Mycoscience, 46,162-183.http://dx.doi.org/10.1007/S10267-005$\underline{0235-Y}$

Aoki, T., Tanaka, F., Suga, H., Hyakumachi, M., Scandiani, M. M., O'Donnell, K. 2012. Fusarium azukicola sp. nov., an exotic azuki bean root-rot pathogen in Hokkaido, Japan. Mycologia, 104, 1068-1084.http://dx.doi.org/10.3852/11-303 Brar, H.K., Swaminathan, S., Bhattacharyya, M.K. 2011. The Fusarium virguliforme toxin FvTox1 causes foliar sudden death syndrome-like symptoms in soybean. Molecular Plant Microbe Interactions, 24, 1179 1188.http://dx.doi.org/10.1094/MPMI-12-10-0285

Brzostowski, L.F.M., Schapaugh, W.T., Rzodkiewicz, .P.A. 2014. Effect of host resistance to Fusarium virguliformae and Heterodera glycines on sudden death syndrome disease severity and soybean yield. Plant Health Progress, 15, 1-8.

Gao, X., Hartman, G., Niblack, T. 2006. Early infection of soybean roots by Fusarium solani f. sp. glycines. Phytopathology, 96, S38.

Gopal, R., Na, H., Seo, C.H., Park, Y. 2012. Antifungal activity of (KW)n or (RW)n peptide against Fusarium solani and Fusarium oxysporum. Internationa 
Journal of Molecular Science, $13, \quad 15042$ 15053.http://dx.doi.org/10.3390/ijms131115042

Gray, L.E. 1996. Severity of foliar symptom and root and crown rot of soybean inoculated with various isolates and inoculum rates of Fusarium solani. Plant Disease, 80, 1197-1199.http://dx.doi.org/10.1094/PD-80-1197

Hartman, G.L., Huang, Y.H., Nelson, R.L., Noel, G.R. 1997. Germplasm evaluation of Glycine max and resistance to Fusarium solani, the causal organism of sudden death syndrome. Plant Disease, 81, 515518.http://dx.doi.org/10.1094/PDIS.1997.81.5.515

Hsuan, H.M., Salleh, B., Zakaria, L. 2011. Molecular identification of Fusarium species in Gibberella fujikuroi species complex from rice and maize from Peninsular Malaysia. International Journal of Molecular Science, 12, 67226732.http://dx.doi.org/10.3390/ijms12106722

Jasnic, S.M., Vidic, M.B., Bagi, F.F., Dordevic, V.B. 2005. Pathogenicity of Fusarium species in soybean. Matica Srpska Proceedings for Natural Science Novi Sad, 109, 113-121.http://dx.doi.org/10.2298/ZMSPN0519113J

Jin, H., Hartman, G. L., Nickell, C.D., Widholm, J.M. 1996. Characterization and purification of a phytotoxin produced by Fusarium solani, the causal agent of soybean sudden death syndrome. Phytopathology, 86, $277-$ 282.http://dx.doi.org/10.1094/Phyto-86-277

Jung, Y.S., Kim, Y.T., Yoo, S.J., Kim, H.G. 1999. Mycological characteristics of Fusarium solani f. sp. pisi isolate from pea, ginseng and soybean in Korea. Plant Pathology Journal, 15, 44-47.

Leandro, L.F.S., Robertson, A.E., Mueller, D.S., Yang, X.B. 2013. Climatic and environmental trends observed during epidemic and non-epidemic years of soybean sudden death syndrome in Iowa. Plant Management Network.

Leslie, J.F., Summerell, B. A. 2006. The Fusarium laboratory manual. Ames, IA, USA, Blackwell Publ. http://dx.doi.org/10.1002/9780470278376

Li, S., Hartman, G.L., Widholm, J.M. 1999. Viability staining of soybean suspension-cultured cells and a seedling stem cutting assay to evaluate phytotoxicity of Fusarium solani f. sp. glycines filtrates. Plant Cell Reports, 18 375-380.http://dx.doi.org/10.1007/s002990050589

Luo, Y., Myers, O., Lightfoot, D. A., Schmidt, M. E. 1999. Root colonization of soybean cultivars in the field by Fusarium solani f.sp. glycines. Plant Disease 83, 1155-1159.http://dx.doi.org/10.1094/PDIS.1999.83.12.1155

Malvic, D.K., Bussey, K. E. 2008. Comparative analysis and characterization of the soybean sudden death syndrome pathogen Fusarium virguliforme in the northern United States. Canadian Journal of Plant Pathology, 30, 467-476. http://dx.doi.org/10.1080/07060660809507544

Marasas, W.F.O., Ploetz, R.C., Wingfield, M.J., Wingfield, B.D., Steenkamp, E.T. 2006. Mangomal formation disease and the associated Fusarium species. Phytopathology, 96, 667-672.http://dx.doi.org/10.1094/PHYTO-96-0667

Marburger, D.A., Venkateshwaran, M., Conley, S.P., Esker, P.D., Lauer, J.G., Ane, J.M. 2014. Crop rotation and management effect on Fusarium spp. populations. Crop $\quad$ Sciences, 365376.http://dx.doi.org/10.2135/cropsci2014.03.0199

Martinelli, J. A., Bocchese, C. A.C., Xie, W., O'Donnell, K., Kistler, H. C. 2004 Soybean pod blight and root rot caused by lineages of the Fusarium graminearum and the production of mycotoxins. Fitopatologia Brasileira, 29, 492-498.http://dx.doi.org/10.1590/S0100-41582004000500004

Matuo, T., Snyder, W.C. 1973. Use of morphology and mating populations in the identification of formae speciales in Fusarium solani. Phytopathology, 63, 562565.http://dx.doi.org/10.1094/Phyto-63-562

Mclean, K.S., Lawrence, G.W. 1995. Development of Heterodera glycines as affected by Fusarium solani, causal agent of sudden death syndrome of soybean. Journal of Nematology, 27, 70-77.

Mueller, D.S., Hartman, G.L., Nelson, R.L., Pedersen, W. L. 2002. Evaluation of Glycine max germplasm for resistance to Fusarium solani f. sp. glycines. Plant Disease, 86, 741-746.http://dx.doi.org/10.1094/PDIS.2002.86.7.741

Navi, S.S., Yang, X.B. 2008. Foliar symptom expression in association with early infection and xylem colonization by Fusarium virguliforme (formerly $F$. solani $\mathrm{f}$ sp. glycines), the causal agent of soybean sudden death syndrome. Plant Health Progress, Online.

Naim, Z., Razak, A. A., Salleh, B. 2008. Bakanae disease of rice in Malaysia and Indonesia: Etiology of the causal agent based on morphological, physiological and pathogenicity characteristics. Journal of Plant Protection Research, 48, 476485 .

Nirenberg, H.I. 1995. Morphological and phytopathological differentiation of Fusarium strains within the Martiella section. In International Seminar on Fusarium Mycotoxins, Taxonomy and Pathogenicity, 9-13 May 1995, Martina Franca, Italy, p 147

O'Donnell, K., Kistler, H.C., Cigelnik, E., Ploetz, R.C. 1998. Multiple evolutionary origins of the fungus causing Panama disease of banana: concordant evidence from nuclear and mitochondrial gene genealogies. Proceedings of the National Academy of Sciences of the United States of America, 95, 20442049.http://dx.doi.org/10.1073/pnas.95.5.2044

O'Donnell, K. 2000. Molecular phylogeny of the Nectria haematococcaFusarium solani species complex. Mycologia, 92, 919938.http://dx.doi.org/10.2307/3761588
O'Donnell, K., Sarver, B.A.J., Brand, T.M., Chang, D.C., Noble-Wang, J., Park, B.J., Sutton, D.A., Benjamin, L., Lindsley, M., Padhye, A., Geiser, D.M., Ward, T.J. 2007. Phylogenetic diversity and microsphere array-based genotyping of human pathogenic Fusaria, including isolates from the multistate contact lensassociated U.S. keratitis outbreaks of 2005 and 2006. Journal of Clinical Microbiology, 45, 2235-2248.http://dx.doi.org/10.1128/JCM.00533-07

Pudake, R.N., Swaminathan, S., Sahu, B.B., Leandro, L.F., Bhattacharyya, M.K. 2013. Investigation of the Fusarium virguliforme fvtox 1 mutants revealed that the FvTox1 toxin is involved in foliar sudden death syndrome development in soybean. Current Genetics, 59, 107-117.http://dx.doi.org/10.1007/s00294-0130392-Z

Roy, K.W., Rupe, J.C., Hershman, D.E., Abney, T.S. 1997. Sudden death syndrome of soybean. Plant Disease, 81, 11001111.http://dx.doi.org/10.1094/PDIS.1997.81.10.1100

Rupe, J.C., Correll, J.C., Guerber, J.C., Becton, C.M., Gbur, E.E., Cummings, M.S., Yount, P.A. 2001. Differentiation of the sudden death syndrome pathogen of soybean, Fusarium solani f. sp. glycines, from other isolates of $F$. solani based on cultural morphology, pathogenicity and mitochondrial DNA restriction fragment length polymorphisms. Canadian Journal of Botany, 79, 829835.http://dx.doi.org/10.1139/cib-79-7-829

SAS, Institute. 2002. The SAS system for Windows. Version 9.2. Cary, NC, SAS Inst.

Swoboda, C.M. 2010. Effect of agronomic practices on sudden death syndrome of soybean in Iowa. Graduate Theses and Dissertations. Paper 1559

Tamura, K., Dudley, J., Nei, M., Tamura, S. 2007. Mega4: Molecular evolutionary genetics analysis (Mega) software version 4.0. Molecular Biology and Evolution, 24, 1596-1599.http://dx.doi.org/10.1093/molbev/msm092

White, T.J., Bruns, T., Lee, S., Taylor, J. 1990. Amplification and direct sequencing of fungal ribosomal RNA genes for phylogenetics. In: Innis MA, et al., (eds), PCR protocols: a guide to methods and applications. San Diego, USA Academic Press, pp 315-322.http://dx.doi.org/10.1016/b978-0-12-3721808.50042-1

Wrather, J.A., Anderson, T. R., Arsyad, D.M., Gai, J., Ploper, L. D., PortaPuglia, A., Ram, H.H., Yorinori, J.T. 1997. Soybean disease loss estimates for the top 10 soybean producing countries in 1994. Plant Disease, 81, 107110.http://dx.doi.org/10.1094/PDIS.1997.81.1.107

Wu, T.G., Keasler, V.V., Mitchell, B.M., Wilhelmus, K.R. 2004 Immunosuppression affects the severity of experimental Fusarium solani keratitis. The Journal of Infection Diseases, 190, 192198.http://dx.doi.org/10.1086/421300

Xing, L.J, Westphal, A. 2013. Synergism in the interaction of Fusarium virguliforme with Heterodera glycines in sudden death syndrome of soybean. Journal of Plant Disease and Protection, 120, 209217.http://dx.doi.org/10.1007/BF03356477

Yang, X.B., Navi, S.S. 2003. Fungal colonization in phloem/xylem tissues of taproots in relation to foliar symptoms expression of soybean sudden death syndrome. Phytopathology, 93, S92.

Zaccardelli, M, Vitale, S., Luongo, L., Merighi, M., Corazza, L. 2008. Morphological and molecular characterization of Fusarium solani isolates Journal of Phytopathology, 156， 534-541.http://dx.doi.org/10.1111/j.14390434.2008.01403.x

Zhang, N., O'Donnell, K., Sutton, D. A., Nalim, F. A., Summerbell, R.C. Padhye, A. A., Geiser, D.M. 2006. Members of the Fusarium solani species complex that cause infections in both humans and plants are common in the environment. Journal of Clinical Microbiology, 44, 21862190.http://dx.doi.org/10.1128/JCM.00120-06 